\title{
POLÍTICAS ASSISTENCIAIS E A PRODUÇÃO DE SUJEITOS VULNERÁVEIS: O PROCESSO DE DESINSTITUCIONALIZAÇÃO PRODUZINDO ZONAS DE ABANDONO SOCIAL
}

\author{
ASSISTANCE POLICIES AND THE VULNERABLE SUBJECTS \\ PRODUCTION: THE DEINSTITUTIONALIZATION PROCESS PRODUCING \\ SOCIAL ABANDONMENT ZONES
}

Renata Lemes Allram - as.renatalemes@gmail.com

Gabriela Felten da Maia - gabryelamaia@gmail.com

\begin{abstract}
RESUMO
O presente artigo visa trazer a tona as particularidades de um município de médio porte, do interior do Rio Grande do Sul, que acabou chamando a atenção por ser conhecido como "depósito de gente", visto o grande número de instituições privadas de caráter asilar que mantinham mais de 600 pessoas institucionalizadas, entre idosos, pessoas com deficiência e sofrimento psíquico. Com denúncias de violação aos direitos humanos, o cenário apresenta-se como zonas de abandono social, com a anuência, de certa forma, do poder público. Por essa razão foi alvo de intervenção de órgãos de garantia de direitos humanos com vista a modificar o quadro que se apresentava. Considerando esse contexto, objetivamos discutir as ambiguidades e tensões na constituição do processo de desinstitucionalização, refletindo sobre o modo como as políticas assistenciais produziram zonas de abandono na medida em que buscavam proteger pessoas consideradas em situação de vulnerabilidade. Para tanto, a análise parte da observação participante, análise dos documentos produzidos ao longo do processo, tais como atas de reuniões e relatórios técnicos e fala dos demais atores sociais envolvidos - profissionais que atuam nos órgãos e serviços da cidade e de outras regiões do estado, residentes, gestores, trabalhadores e proprietários das casas asilares. Inicia-se apresentando uma genealogia deste processo de desinstitucionalização e as discussões fomentadas em âmbito das políticas públicas municipais, principalmente, a visão dos técnicos de assistência social, bem como o lugar desta no quadro em tela, especificamente, reflete-se as particularidades dessa problemática na rede de garantia de direitos municipal e o panorama encontrado para pensar o lugar da assistência social neste processo.
\end{abstract}

Palavras-chave: Desinstitucionalização; Assistência social; Precariedade.

\begin{abstract}
This article aims to bring to light the peculiarities of a medium-sized municipality, in the interior of Rio Grande do Sul, which ended up drawing attention because it is known as a "deposit of people", considering the large number of private asylum institutions that maintained more than 600 people institutionalized, among the elderly, people with disabilities and psychic suffering. With denunciations of human rights violations, the scenario presents itself as zones of social abandonment, with the consent, in a certain way, of the public power. For this reason, it was the target of intervention by human rights bodies with a view to changing the situation. Considering this context, we aimed to discuss the ambiguities and tensions in the constitution of the process of deinstitutionalization, reflecting on the way in which welfare policies have produced abandonment zones insofar as they seek to protect people considered to be vulnerable. To do so, the analysis starts with participant observation, analysis of the documents produced during the process, such as minutes of meetings and technical reports and talks about other social actors involved - professionals who work in the organs and services of the city and other
\end{abstract}




\section{Nanduty}

ISSN:2317-8590

regions of the state, residents, managers, workers, and homeowners. It begins by presenting a genealogy of this process of deinstitutionalization and the discussions fomented in the scope of the municipal public policies, mainly, the vision of the technicians of social assistance, as well as the place of this in the picture in screen, specifically, reflects the peculiarities of this problematic in the municipal rights guarantee network and the panorama found to think about the place of social assistance in this process.

Keywords: Deinstitutionalization; Social assistance; Precariousness.

\section{INTRODUÇÃO}

A questão da saúde mental não deve se restringir apenas a política pública de saúde, devendo ser pautada intersetorialmente em outras políticas sociais. Entretanto, a partir da experiência de desinstitucionalização em curso no município de Cachoeira do Sul, localizado na região central do Estado do Rio Grande do Sul, ficou evidente que este entendimento não é uníssono entre os/as profissionais da assistência social, ficando a cargo do julgamento e identificação do/a técnico/a em cada situação. A cidade possui um número significativo de casas asilares de caráter privativo que abrigam em torno de 600 pessoas, entre idosos, pessoas com deficiência e sofrimento psíquico. Essa experiência trouxe certa visibilidade tanto no Estado do Rio Grande do Sul quanto em nível nacional, na mídia e pelos órgãos de garantia de direitos humanos, em razão de denúncias realizadas pelo Conselho Municipal de Assistência ao Idoso (COMAI) sobre as diversas formas de violação aos direitos humanos nas diferentes instituições de longa permanência existentes no município.

A visibilidade desse cenário culminou, em dado momento, na reunião dos Ministérios da Saúde e do Desenvolvimento Social e Combate a Fome ${ }^{1}$ (órgãos nacionais incumbidos de nortear as diretrizes das políticas públicas de saúde e assistência social, respectivamente), a Secretaria Nacional dos Direitos Humanos (reguladora do Disque 100) e os equivalentes em níveis estaduais, Secretaria Estadual de Saúde e Departamento Estadual de Assistência Social, e municipais, Secretaria Municipal de Saúde e Secretaria de Trabalho e Ação Social, com seus devidos equipamentos. Portanto, diferentes setores e atores foram acionados para que se pudesse

1No início do processo de desinstitucionalização nomeava-se Ministério do Desenvolvimento Social e Combate à Fome. Posteriormente, com a troca de gestão (o golpe de 2016), passou a ser nomeado Ministério do Desenvolvimento Social e Agrário. No decorrer do texto, será mantido a nomenclatura da época em que aconteceram os fatos narrados. 


\section{Nanduty}

ISSN:2317-8590

pensar ações e estratégias de enfrentamento e transformação de uma situação que se tornava insustentável manter, colocando em evidência diferentes concepções sobre o que significa cuidado em liberdade, política de saúde mental e o lugar de cada setor no processo de desinstitucionalização.

Entendendo que as políticas públicas não são neutras, mas marcadas por relações de poder e, portanto, produzindo efeitos contraditórios, entendemos ser importante discutir esse processo de desinstitucionalização porque passa o município em seu caráter dinâmico e heterogêneo. Partimos de uma leitura que entende o Estado dessubstancializado, dado que se compreende que este é feito na prática, a partir de diferentes dinâmicas, implicando o processo de participação de diferentes atores e conforme o contexto em que as políticas públicas são operacionalizadas. A formulação destas, como diz Shore (2010), é uma atividade sociocultural, imersa em processos sociais cotidianos, em mundos de sentidos, frentes discursivas e práticas culturais. Assim, "el análisis de las políticas públicas implica dar sentido al conocimiento tácito, a las múltiples interpretaciones, y a menudo a las definiciones en conflicto que las políticas tienen para los actores situados en lugares diferentes" (Shore 2010: 24).

Trata-se, então, de mapear o Estado pelas suas margens enquanto espaços de experimentação, como práticas em que a lei e as intervenções estatais passam por outras formas de regulação que provêm das necessidades das populações consideradas vulneráveis. Uma perspectiva, portanto, que contrapõe a leitura espacial que produz uma imagem verticalizada ou de solidez do Estado para descer até o chão e vê-lo nos interstícios das infraestruturas que redefinem no cotidiano as políticas públicas, produzindo-o a todo instante (Biehl 2008; Das \& Poole 2008). Nesse sentido, reflete-se sobre a formulação das políticas pelos seus efeitos, dando ênfase ao modo como o processo de desinstitucionalização permite que evidenciemos as contradições e diferentes sentidos dados pelos atores a uma situação que constitui a cidade como um “depósito de gente" em instituições asilares.

Para esta análise, foram consultados documentos produzidos durante a discussão, compilação dos dados levantados nas instituições, atas das reuniões, observação do trabalho desenvolvido pelos atores envolvidos - técnicos/as da rede municipal, entes federados, servidores do ministério público, proprietários das instituições, residentes e técnicos/as de outros municípios. Esses diferentes materiais 


\section{Nanduty}

ISSN:2317-8590

foram resultados da participação intensa de uma das autoras desde as etapas iniciais do processo de desinstitucionalização e do acompanhamento das reuniões de trabalho intersetorial, compilados em um diário de campo.

O objetivo será discorrer o início deste processo de desinstitucionalização e as discussões fomentadas em âmbito das políticas públicas municipais, principalmente, a visão dos/as técnicos/as de assistência social, bem como o lugar desta no quadro em tela. Por isso, será importante refletir criticamente sobre as definições do processo de desinstitucionalização, seguindo um breve histórico deste e alguns passos desta longa trajetória que se enuncia, para, então, refletir sobre a perspectiva da política pública de assistência social neste caso. Dando seguimento, discute-se as particularidades dessa problemática na rede de garantia de direitos municipal e o panorama encontrado para pensar o lugar da assistência social neste processo.

\section{POLÍTICAS ASSISTENCIAIS E DESINSTITUCIONALIZAÇÃO PRODUZINDO ZONAS DE ABANDONO}

O desafio de entender as políticas públicas em seu caráter dinâmico nos coloca a necessidade de pensar o Estado como um projeto permanentemente incompleto, constituído a partir dos processos de lutas que envolvem diferentes atores sociais, produção de novas subjetividades e novos sujeitos políticos a serem incorporados. Como coloca Shore (2010), as políticas públicas são marcadas por uma rede heterogênea e complexa de atores e instituições que, em ação, produzem efeitos que ultrapassam o seu desenho e os objetivos propostos inicialmente pelos agentes formuladores. Portanto, a atenção ao contexto local de implementação de uma política pública torna-se necessária para compreendermos essa dinamicidade e os mecanismos de funcionamento ocultados por uma perspectiva legal-racional dada às mesmas.

Nesse sentido, convém dar atenção a relação entre Estado e suas margens, como um espaço entre corpos, lei e disciplina, para discutir a constituição de um crescente campo de cuidado institucional que produz zonas de abandono social diante do contexto da reforma psiquiátrica e a instituição de um marco legal de cuidado em liberdade em saúde mental. Zonas de abandono, como diz Biehl (2008), a serviço de um modo de governar as populações e que possibilita-nos capturar a lógica das infraestruturas cotidianas que fazem com que certas vidas ganhem formas e outras sejam 


\section{Nanduty}

ISSN:2317-8590

impossibilitadas.

Trata-se de pensar o corpo sob um poder biopolítico em que não mais se faz morrer ou deixa viver, mas se deixa morrer para fazer outros viverem (Foucault 2002), pois está relacionada a questão da produção da exclusão, na medida em que para garantir a vida é preciso reduzir algumas a espécies matáveis. Fassin (2005) e Biehl (2008) demonstram como as políticas públicas operam uma política da vida que produz formas de abandono social conduzindo práticas de exclusão de determinados corpos seja pela condução de critérios de eleição de beneficiários ou pelo afastamento de determinados sujeitos que por sua corporalidade são marcados pela ausência da dinâmica de reconhecimento de suas vidas como viáveis.

Nesse sentido, Agamben (2002), na esteira da discussão foucaultiana de biopolítica, reflete sobre a vida nua enquanto um acontecimento biopolítico, uma vida que já não se pode dispor e que passa a ser exposta à morte. Apontando os campos de concentração como metáforas da biopolítica moderna, esse autor indica essa dimensão como uma forma de pensar em quais são os espaços de extermínio não oficial em que sujeitos são deixados à mercê da morte. Nessa perspectiva, nos possibilita pensar que há locais em que alguns estão fora estando incluídos, quando há vidas que são precarizadas, sujeitos que são subjetivados sob a ideia de vulnerabilidade e que devem ser "cuidados" pela sua condição de deficientes/velhos/doentes mentais. Portanto, vidas que são desqualificadas dentro de processos democráticos, empurrados para essas zonas de abandono.

Então, como uma política de assistência às pessoas de mais idade transforma-se em uma máquina de precarização de vidas, intensificando processos de sofrimento social? Como a despeito da reforma psiquiátrica, o modelo de cuidado às pessoas de mais idade mantém o modelo manicomial, coexistindo com outras lógicas de cuidado em saúde mental? Quando categorias como velhice e deficiência operacionalizam estratégias de precarização que levam ao enquadramento de inaptidão que possibilita a institucionalização?

São essas e outras questões que nos indicam a complexidade desse processo de desinstitucionalização e que convém questionar as relações manicomiais de poder e de saber que tem produzido o contexto de Cachoeira do Sul como uma zona de abandono social de pessoas em casas-lares privadas. Antes de pensar esse contexto como uma 


\section{Nanduty}

ISSN:2317-8590

dificuldade de construir uma política de cuidado em consonância com as diretrizes do processo de Reforma Psiquiátrica e a construção de um trabalho dentro de uma nova perspectiva de saúde mental, convém refletir a heterogeneidade do contexto local para entender o processo de institucionalização e desinstitucionalização em curso no município.

A reforma psiquiátrica é considerada um importante marco na luta antimanicomial por propor uma mudança na lógica do cuidado através do confinamento, propondo a extinção do modelo hospitalocêntrico de tratamento da loucura para modelos de acompanhamento terapêutico através de serviços substitutivos, hospitaisdia, residenciais terapêuticos, etc. Trata-se de uma mudança paradigmática no ordenamento jurídico, resultado de uma longa trajetória de embates e experiências calamitosas, como Barbacena 2, para que se modificasse a política de saúde mental.

Até a reforma psiquiátrica o "cuidado" se dava pela segregação e banimento destes "loucos" (ou apenas desviantes da considerada normalidade), separando-os da cidade através de muros e do confinamento em asilos e grandes hospitais, submetidos a toda sorte de infortúnios. Tratamento degradante, vexatório e em condições desumanas eram comuns. Com a promulgação da Lei de Reforma Psiquiátrica em 2001, o modelo hospitalocêntrico e manicomial foi sendo desmantelado para a organização de uma política de saúde mental com uma lógica de cuidado em liberdade-. Visa garantir o cuidado ao paciente com sofrimento psíquico em serviços substitutivos aos hospitais psiquiátricos, superando assim a lógica das internações de longa permanência que tratam o/a sujeito isolando-o do convívio com a família e com a sociedade como um todo.

Nesse período, cuidado de pessoas de mais idade também passa por mudanças. Mais abrangente que a Política Nacional do Idoso, lei de 1994 que dava garantias às pessoas com mais de 60 anos, o Estatuto do Idoso institui penas severas para quem desrespeitar ou abandonar cidadãos de mais idade. Promulgado em 2003, o estatuto

2Barbacena foi o cenário do maior genocídio já registrado no Brasil. A cidade era sede do Hospital Colônia, criado inicialmente para tratar pessoas com sofrimento psíquico, mas que recebia, em sua maioria, os "indesejáveis" da sociedade como pessoas em situação de rua, mães solteiras, pobres, homossexuais e militantes. A história desse hospital está documentada no livro e documentário intitulado "O holocausto brasileiro, de autoria da jornalista Daniela Arbex, publicados, respectivamente, em 2013 e 2016. O livro foi eleito o melhor livro-reportagem do ano pela associação paulista de críticos de arte, em 2013, e o segundo melhor livro-reportagem no prêmio Jabuti, em 2014. 


\section{Nanduty}

ISSN:2317-8590

estabelece defesa da cidadania dos cidadãos e cidadãs dessa faixa etária, dando-lhes ampla proteção jurídica para usufruir direitos sem depender de favores, amargurar humilhações ou simplesmente para viverem com dignidade. O Estatuto pincela ainda as características das instituições de longa permanência para idosos e, dois anos após, a Agência Nacional de Vigilância Sanitária promulga um regulamento técnico para o funcionamento das Instituições de Longa Permanência para Idosos (ILPI's), através da Resolução RDC 283/2005.

No município de Cachoeira do Sul, a constituição desse processo de implementação de uma política de saúde mental, embora não instituída com marco legal, é construída através dos profissionais na sua prática cotidiana, materializada nos Centros de Atenção Psicossocial (dos tipos II e Ad) e também através das casas lares privados. Até o ápice do processo - a interdição judicial da maior casa asilar do município - os únicos equipamentos específicos de cuidado em saúde mental, eram esses serviços. Com esta intervenção, que teve grande suporte do Estado do Rio Grande do Sul, foram criados dois Serviços de Residenciais Terapêuticos municipais, com incentivo financeiro inicial estatal.

A cidade em termos de rede socioassistencial de atendimento à população, no âmbito de saúde e assistência social, tem os equipamentos que estão aquém do previsto pelas diretrizes dos Ministérios da Saúde e do Ministério do Desenvolvimento Social e Combate à Fome. De acordo com o Cadastro Nacional de Estabelecimentos de Saúde CNES, os equipamentos de atenção psicossocial compõem-se de 01 unidade de pronto atendimento, 02 centros de atenção psicossocial (II e Ad), 19 unidades sanitárias, 07 equipes de estratégias de saúde da família, 01 hospital geral, 01 ambulatório e 02 equipes de agentes comunitários de saúde. Com relação aos dados buscados junto ao cadastro do sistema único de assistência social, CadSUAS, encontra-se 03 centros de referência de assistência social (CRAS), 01 centro de referência especializado de assistência social (CREAS), 01 unidade de acolhimento institucional de crianças e adolescentes e 01 equipe volante. Todavia é sabido que embora expressivo em número de equipamentos, muitos destes não operam com as equipes completas conforme preconizam as diretrizes legais.

Convém ressaltar que os residentes das instituições com características asilares acessam os serviços de saúde pública basicamente para consultas e dispensa de 


\section{Nanduty}

ISSN:2317-8590

medicação da rede básica. Em relação a rede de assistência, é quase inexpressivo o seu acesso.

Entre as políticas de atenção à população idosa, há um grande número de instituições de longa permanência de caráter privado que alcança a marca de 22 instituições no total. Estas abrigavam, em 2012, ano do primeiro levantamento, 666 pessoas. Destas, 397 eram residentes de Cachoeira e 269 oriundas de diversos outros municípios do Estado; 404 idosos e 262 abaixo de 60 anos. Inicialmente criadas para acolher idosos, estas instituições hoje abrigam também pessoas com deficiência e diagnosticados com sofrimento psíquico grave, ambos em idade inferior e superior a 60 anos.

Conferindo in loco cada uma delas, o Conselho Municipal do Idoso defrontou-se com uma realidade até então desconhecida da rede de proteção, no que se refere a pessoa idosa, fazendo com que se formalizasse perante o Ministério Público uma denúncia de violação de direito. Inicia-se, assim, um processo de desinstitucionalização que envolveu vários órgãos, setores e serviços; visando a integração de recursos multidisciplinares, intersetoriais e transdisciplinares, numa necessidade de agregar competências e alinhar as ações.

Talvez podemos compreender que esta lacuna de serviços públicos para o cuidado em liberdade tenha sido a oportunidade aproveitada para a formação do grande número de casas privadas, no modelo manicomial, mesmo após a reforma psiquiátrica. Sem equipamentos substitutivos, recursos humanos para acompanhamento familiar e fiscalização deficitária, esse modelo empresarial/privado torna-se alternativa. Rentável para os empresários - que ofertam o mínimo com custo baixo e ainda se utilizam do sistema único de saúde (como a dispensa de medicação e consultas) e conveniente para as famílias, que não encontram no poder público apoio adequado para o cuidado com seu familiar.

Essa situação se configura há bastante tempo, cerca de 20 anos, conforme relatos colhidos por atores da rede socioassistencial junto a conselhos de direitos e aos proprietários dos estabelecimentos. Porém, não é encontrado no município, registro que determine o início desta "proliferação" de instituições. Mas o que esse processo evidencia é o apoio dos serviços públicos municipais que, na ausência de equipamentos públicos, técnicos do município acabavam por recorrer a estas casas ao se encontrarem, 


\section{Nanduty}

ISSN:2317-8590

muitas vezes, no dilema de garantir a sobrevivência ou garantir direitos aos usuários. Entretanto, esta prática não era refletida criticamente entre a categoria, especialmente da Assistência Social, que, em muitos casos, fez uso desse recurso para a proteção de usuários que chegavam até os equipamentos.

\section{GENEALOGIA DE UM PROCESSO DE (DES)INSTITUCIONALIZAÇÃO}

No ano de 2007, houve, por parte do Ministério Público, intensificação na fiscalização das instituições de moradia, em caráter asilar, em Cachoeira do Sul. Tal ação se deve pelas denúncias do COMAI que assinalava o progressivo acréscimo de pessoas com sofrimento psíquico abaixo de sessenta anos nestes locais. Este quadro se deu quando alguns pacientes do Instituto Psiquiátrico Forense (IPF) tiveram suas Medidas de Segurança extintas ou foram decretadas suas Altas Progressivas e, desse modo, encaminhados para as casas asilares em Cachoeira do Sul. Era necessário um local para que os usuários que já haviam cumprido sua pena e não possuíam mais família pudessem encontrar um lugar para acolhê-los e residir, mas a escolha do município, segundo os/as profissionais daquele órgão, se deu por casualidade.

Segundo relatório da Secretaria Estadual de Saúde, elaborado após o mutirão dos censos em duas primeiras casas, foi criado nesta época (2007), um grupo de trabalho denominado "Qorpo Santo", composto por órgãos estaduais, que tinha como propósito trabalhar a reinserção destes usuários na sociedade, buscando locais adequados de moradia, trabalho e acompanhamento em saúde. Devido à troca de gestão no governo, em 2010, o grupo encerrou suas atividades.

Nos anos de 2011 e 2012, o Ministério Público retoma a questão com a formação de uma rede de cooperação para a fiscalização de ILPI's, com representantes de órgãos da rede estadual e municipal. Esta ação resultou na entrada do grupo em 19, das 22 instituições existentes na época, objetivando produzir retrato fiel dos estabelecimentos, em sua estrutura física, de recursos humanos e materiais, bem como do número de residentes idosos e com sofrimento psíquico; e da linha de cuidado dispensadas a estes. Todas as instituições presentes no município são de natureza privada, contrariando as portarias 106/2000 e 3090/2011 do Ministério da Saúde e 


\section{Nanduty}

ISSN:2317-8590

109/2009 do Ministério do Desenvolvimento Social e Combate à Fome ${ }^{3}$.

O quadro que se apresentou após este primeiro passo foi alarmante. Ao final das diligências, o grupo deparou-se com espantosos 614 pessoas acolhidas nas 19 instituições mencionadas; não havendo, muitas vezes, divisão dos segmentos. A parte estrutural em muitas delas estava em desacordo com a legislação vigente, os recursos humanos e materiais insuficientes e o cuidado dispensado aos acolhidos precário. Outra situação levantada que merece destaque, é o grande número de acolhidos originários de outros municípios do Rio Grande do Sul. Resguardadas as proporções, Cachoeira do Sul é a cidade do interior do estado com maior concentração de pessoas em sofrimento psíquico e deficiência física institucionalizados em equipamentos privados de caráter asilar.

Pouco após a compilação dos dados, constata-se que uma das instituições, que abrigava 39 pessoas com sofrimento psíquico e que era alvo de investigação por parte do Ministério Público por maus tratos, foi fixar-se na cidade de Viamão. O caso foi tratado como sequestro, já que a dirigente do local teria removido os acolhidos sem autorização judicial - grande parte deles oriundos do Instituto Psiquiátrico Forense.

No ano de 2013, tal quadro foi levado ao Centro de Apoio Operacional dos Direitos Humanos (CAO), do Ministério Público Estadual, o qual convocou as Secretarias de Estado da Saúde (SES), da Justiça e dos Direitos Humanos (SJDH) e do Trabalho e do Desenvolvimento Social (STDS) para tomarem as providências cabíveis ao poder executivo estadual e até ao executivo federal. Inúmeras reuniões foram realizadas entre os três poderes: Federal (Ministério da Saúde, Ministério do Desenvolvimento Social e Combate à Fome, Secretaria Nacional dos Direitos Humanos), Estadual (Secretaria Estadual de Saúde, $8^{\text {a }}$ Coordenadoria Regional de Saúde, Ministério Público Estadual, Secretaria do Trabalho e Desenvolvimento Social) e Municipal (Secretaria Municipal de Saúde e Secretaria Municipal do Trabalho e Ação Social); sem, contudo, ações mais concretas se realizarem no âmbito das políticas públicas para, ao menos, minimizar as violações de direitos que foram constatadas no primeiro mutirão de entrada nas ILPI's.

3Portaria 106/2000 portaria 3090/2011 do MS dispõe acerca dos Serviços Residenciais Terapêuticos em Saúde Mental e resolução 109/2009 do MDS que aprova a Tipificação Nacional dos Serviços Socioassistenciais. 


\section{Nanduty}

ISSN:2317-8590

Ainda neste ano, foi instaurado pelo Ministério Público inquérito civil visando apurar a omissão do município, no qual resultou na assinatura de um termo de ajustamento de conduta (TAC), como forma de evitar o aumento do número de pessoas asiladas na cidade; ensejando na promulgação do Decreto Municipal 120/2013. Mesmo com a legislação federal, a Lei da Reforma Psiquiátrica, que impedia o ingresso de pessoas não idosas em situação similar, desde 2001, foi necessário a adoção dessa medida para que a abertura de novas casas de longa permanência, para abrigar pessoas em sofrimento psíquico com idade inferior a 60 anos, bem como o encaminhamento de novos pacientes com essas características às casas já existentes, fosse vedada.

Em abril de 2014, foi instaurado um Grupo de Trabalho constituído por representantes da Secretaria Especial de Direitos Humanos da Presidência da República, Ministério da Saúde, Ministério do Desenvolvimento Social e Combate à Fome, Secretaria Estadual de Saúde/RS, Secretaria de Justiça e Direitos Humanos/RS, Secretaria de Trabalho e Desenvolvimento Social/RS, Secretaria Municipal Saúde e Secretaria Municipal de Desenvolvimento Social de Cachoeira do Sul, coordenado pelo Ministério Público Estadual, cujo objetivo era planejar ações conjuntas entre os entes federativos para a regularização das instituições e desinstitucionalização, conforme projetos terapêuticos singulares (PTS), das pessoas que viviam nas casas lares. Foram realizados encontros sistemáticos e chegou-se a um consenso quanto à metodologia de trabalho (censo clínico e psicossocial), às diretrizes de saúde mental e às recomendações técnicas para o processo de desinstitucionalização.

Paralelamente a estas ações, ainda em 2014, foi garantido pelo Estado do RS recurso financeiro (no valor de mais de $\mathrm{R} \$ 976.000,00$ ) para ações emergenciais de desinstitucionalização. Contudo, era necessário votação do Legislativo Municipal para aplicação desse recurso, o que foi negado para o fim desejado (contratação de equipe para a realização de Censo Psicossocial e elaboração de Projeto Terapêutico Singular) Reuniões de sensibilização e informação a respeito do processo de desinstitucionalização foram propostas com os vereadores, por parte do MP e do Executivo Municipal, sem a aderência dos mesmos nestes espaços. Na sessão Legislativa para votação, a tribuna foi ocupada por proprietários das casas asilares - que se organizaram em associação na ânsia em manter seus estabelecimentos inalterados por vereadores e representantes do Executivo e MP. Neste ínterim, diversas reportagens 


\section{Nanduty}

ISSN:2317-8590

foram veiculadas na mídia local, formando praticamente um espetáculo midiático, incitando a aceitação social e denotando o viés político partidário da questão.

Com a negativa, houve a realização de uma força-tarefa para a construção do Censo Clínico e Psicossocial dos munícipes de Cachoeira do Sul institucionalizados nas casas asilares Perpétuo Socorro e Lar de Maria (consideradas como as mais calamitosas, incluindo um homicídio entre os residentes em uma delas), com a presença de profissionais do município e do estado. No ano de 2015, especificamente a partir do segundo semestre, com a troca de promotores na comarca e de gestão municipal ao longo do processo, decide-se, mais uma vez, entrar nas instituições para levantamento de dados dos usuários e dos equipamentos, porém de maneira mais concisa que o movimento anterior.

Finalizando o levantamento, chega-se ao número de 666 pessoas institucionalizadas nas, então, 22 casas cachoeirenses. Forma-se, a partir daí, um "novovelho" grupo de trabalho com profissionais de assistência social e saúde para questões referentes ao processo de desinstitucionalização. Na prática, atuavam em casos pontuais, contato com os municípios de origem e contato com os familiares dos cachoeirenses.

De 2007 a 2016, muitas promessas por parte da gestão municipal foram ventiladas e renovadas a cada troca de governo, possibilidades legais foram levantadas também por parte do Ministério Público, até a culminância, em agosto de 2016, mediante ordem judicial, com a interdição da Casa de Repouso Perpétuo Socorro considerada a mais periclitante em termos de violação aos direitos humanos.

$\mathrm{Na}$ "encampação" da Perpétuo Socorro, os proprietários e funcionários foram afastados e uma equipe de trabalhadores do município passou a dispor do cuidado dos 87 residentes que se encontravam institucionalizados no local. Sem dúvida a parte mais dura e dolorosa de todo o processo até então. Ressalta-se que o local chegou a abrigar 112 pessoas no ano de 2015, mas com o falecimento de uns e com o trabalho individualizado dos serviços da rede socioassistencial (e do Ministério Público) de retorno as famílias e aos municípios de origem, à época da intervenção a casa contava com 87 residentes.

Todavia, simplesmente fechar as portas de uma instituição do porte da Casa de Repouso Perpétuo Socorro, sem antes garantir a existência de alternativas de assistência 


\section{Nanduty}

ISSN:2317-8590

não era uma atitude responsável. A culminância do processo judicial do qual o município de Cachoeira do Sul é réu, expôs décadas de omissão do Estado - leia-se o município de Cachoeira do Sul e o Estado do Rio Grande do Sul - com a conjuntura de privatização do "cuidado" em saúde mental.

Para amenizar o caos, dois serviços residenciais terapêuticos - SRT, no âmbito do SUS, foram abertos prioritariamente para os munícipes cachoeirenses. Em termos de política de assistência social, a orientação era de priorizar o processo de desinstitucionalização dentro dos equipamentos existentes já saturados pela excessiva demanda; o que agravou o processo de trabalho e entendimento dos/as técnicos/as que sempre foi divergente.

A Secretaria de Trabalho e Ação Social foi convidada a integrar a primeira rede de cooperação para fiscalização das ILPI's, em 2011. Entretanto, neste primeiro momento não houve participação da STAS, pois o entendimento da gestão da época era de que a política de assistência social não possuía caráter fiscalizador. Todavia, o CREAS responsável pelo atendimento a pessoas e famílias em situação de violência e violação de direitos, passou a receber inúmeras solicitações do Ministério Público para averiguar casos isolados de residentes em ILPI's e denúncias via "Disque 100”. Tal fato chamou a atenção da equipe pelo crescente número de pedidos e de violações encontradas em diversas instituições com o passar dos anos (de 2011 até 2016, quando ocorreu a interdição da Perpétuo Socorro).

Contudo, foi percebido que para resolver esta situação, havia a necessidade de uma organização na sociedade, de modo a respaldar a absorção desse contingente de indivíduos, em cada localidade por serviços de assistência extra-hospitalar, ou, neste caso, extra institucional, pois as ILPI's não são hospitais, tampouco clínicas de assistência à saúde mental. Porém, este trabalho é a longo prazo e deveria ser iniciado pelo entendimento dos próprios técnicos da rede, visando não apenas modificar a nomenclatura, mas evitar os mesmos vícios e propósitos de isolar, segregar, violentar e cassar os direitos humanos e de cidadania (Sadigursky 1998).

Desta forma, a equipe do CREAS visualizou a necessidade de integração das proteções sociais; de média complexidade - a qual este serviço pertence, segundo a tipificação nacional dos serviços socioassistenciais - e a de proteção básica, materializada nos CRAS. Contudo, o entendimento dos/as profissionais divergiu 


\section{Nanduty}

ISSN:2317-8590

durante todo o processo. Várias discussões acerca deste tema, até então, novo e atípico, sucederam-se. Portanto, tornou-se um processo contínuo de construir e desconstruir o trabalho nas intervenções diárias e nos enfrentamentos com os/as técnicos/as da rede interna, principalmente.

A mais comum entre as justificativas era a grande demanda dos serviços aliados a ausência de sensibilização com o tema para, ao fim e ao cabo apresentar uma compreensão da política de assistência social com relação a essa problemática divergente àquela dada pela equipe da média complexidade. Observou-se que não se permitiam refletir que estas instituições, muitas vezes estavam no território do equipamento, servindo de residência para idosos e pessoas com deficiência - e que poderia ser executado o acompanhamento em domicílio, como preconiza a Tipificação no âmbito da proteção básica ou o fortalecimento de vínculos, ou quem sabe ainda o acesso aos documentos civis (pois muitos deles não possuíam toda documentação básica e os proprietários não se importavam em refazer), numa premissa básica de resgate da cidadania. Emerge ainda uma tensão nas relações entre as entidades privadas e o setor público, pela questão de que muitas vezes, na carência de equipamentos e políticas públicas para acolhimento, os/as profissionais recorriam a estas instituições. Por conseguinte, não se autorizavam (moralmente) a cobrar e questionar qual o tipo de cuidado ofertado.

\section{AMBIGUIDADES E TENSÕES NA CONSTITUIÇÃO DO PROCESSO DE DESINSTITUCIONALIZAÇÃO}

O processo pelo qual vem passando o município demonstra a complexidade do que significa desinstitucionalizar e cuidar em liberdade e o modo como as políticas públicas se fazem na produção cotidiana, a partir das possibilidades existentes no contexto local em relação com aspectos macroestruturais econômicos e políticos. Por isso, falar de desinstitucionalização também implica pensar a rede complexa entre local e global em que participam diferentes poderes e atores.

Quando se fala em desinstitucionalização, em geral é a ideia de retirada dos pacientes remanescentes de hospitais psiquiátricos e o processo é associado à política pública de saúde e relacionada, geralmente, às profissões da saúde, como enfermagem, psicologia e medicina. Entretanto, este processo em Cachoeira do Sul teve especial 


\section{Nanduty}

ISSN:2317-8590

participação do serviço social e da política pública de assistência social, uma vez que, além de idosos, as casas asilares contavam com grande número de pessoas com deficiência sem sofrimento psíquico e com menos de 60 anos. A própria dinâmica de organização dessa política de assistência aos idosos, tem uma forte presença da política de assistência social em sua legitimação e continuidade, além da privatização do cuidado diante das lacunas na constituição de políticas de cuidado em saúde e assistência social no município, aliada ao lobby político realizado pelos proprietários e a espetacularização do processo de desinstitucionalização acionando a perspectiva de vulnerabilização e vitimização das pessoas residentes caso se levasse adiante o processo de desinstitucionalizar.

A interdição da Perpétuo Socorro evidenciou essa complexidade da produção das políticas públicas. Vários órgãos já haviam alertado para a grave situação da instituição. O local já havia sido vistoriado pela Vigilância Sanitária Municipal e Estadual, tendo sido aplicadas penalidades e interdição parcial e o último posicionamento destes órgãos era pela interdição total da casa. O local não contava com responsável técnico, os funcionários não possuíam capacitação para exercerem a atividade, o número de cuidadores era insuficiente para o total de moradores. A instituição é formada por corredores estreitos, com desníveis importantes, sem sinalização de rotas de saída e iluminação de emergência e os poucos extintores de incêndio existentes estavam com prazo de validade vencidos, as instalações elétricas estavam em desacordo com as normas técnicas e não havia alvará de prevenção e proteção contra incêndios - PCCI. As condições de higiene eram precárias, não haviam receitas médicas nem prontuários atualizados dos residentes, sendo localizados vários medicamentos sem prescrição. Não havia identificação ou registro de restrições alimentares para os acolhidos hipertensos e diabéticos e a alimentação era insuficiente para o número de residentes, sendo encontrados alimentos com prazo de validade vencidos e em estado de putrefação, bem como não havia água potável acessível aos mesmos.

Foi discorrido ainda sobre o tratamento desumano e a violação da dignidade da pessoa humana a que estavam submetidos os acolhidos. O local trabalhava na contramão dos objetivos da Lei 10.216/01, Lei da Reforma Psiquiátrica, que prevê mudanças no modelo assistencial aos pacientes com sofrimento psíquico, destacando-se 


\section{Nanduty}

ISSN:2317-8590

o processo de desospitalização e o cuidado em liberdade, através de equipamentos substitutivos as internações hospitalares de longa permanência. Numa visita técnica, representantes do Conselho Regional de Serviço Social (CRESS) são enfáticos ao afirmarem "que estamos diante de uma tragédia humana já em curso".

Em 02 de agosto de 2016, o município de Cachoeira do Sul recebe ordem judicial para assumir a gestão financeira e o cuidado dos residentes da Casa de Repouso Perpétuo Socorro em vinte e quatro horas. Desta forma, no dia seguinte, ocorre a "encampação" da instituição. Foi nomeado um interventor para a ação, indicado pelo governo municipal, sendo esta a secretária municipal de saúde que acumulava a pasta de assistência social interinamente. Era o interventor que respondia provisoriamente pela curatela dos residentes interditados cujos curadores eram as proprietárias da entidade. Em 90 dias, o município de Cachoeira do Sul deveria prover o cuidado dos residentes, assumindo a gestão organizacional e financeira do local, prover a desinstitucionalização para os municípios de origem àqueles que não eram provenientes da cidade e, posteriormente, assumir a responsabilidade daqueles que não possuírem condições de retorno aos seus municípios ou famílias.

Num primeiro momento, foi organizado, em regime de "mutirão", uma força tarefa composta de servidores das secretarias de saúde e assistência social, que se revezavam no cuidado aos residentes, na limpeza e manutenção do local, que se encontrava em precárias condições de asseio e conservação. A equipe inicial contava com 05 cuidadores por turno, 02 higienizadores, 01 técnico em enfermagem e 01 enfermeiro, além de técnicos de apoio (assistentes sociais, terapeuta ocupacional, psicólogos/as) e de manutenção (troca de fechaduras, consertos e reparos na estrutura física) que se revezavam em turnos. Esse momento deu-se a apreensão acerca da rotina estabelecida anteriormente e de ajustes a mesma.

Ao entrar no local, primeira impressão era de que estávamos em uma instituição total descrita por Goffman (1961: 11), "um local de residência e trabalho aonde um grande número de indivíduos com situação semelhante, separados da sociedade mais ampla por considerável período de tempo, levam uma vida fechada e formalmente administrada". Os/as residentes deveriam permanecer no "pátio" em que the foi designado (correspondente a "casa" em que residia, separados por demanda - aqueles com sofrimento psíquico - dos idosos). A separação física dos espaços era através de 


\section{Nanduty}

ISSN:2317-8590

grades e portões cadeados. Os idosos, permaneciam o dia inteiro dentro da casa, geralmente na mesma posição em que eram deixados pela manhã, com exceção de alguns residentes, com um pouco mais de autonomia, que andavam pela casa, mas ainda assim, sem ocupar todos espaços disponíveis. Já os residentes com sofrimento psíquico, ocupavam o pátio externo, sem nenhuma atividade específica.

Ficou claramente evidenciado que, em sua grande maioria, os residentes não eram estimulados em relação a sua autonomia, aguardando sempre autorizações para circularem, irem para a área externa tomar sol ou qualquer outra atividade. Como consequência do ócio, percebeu-se que o tempo era ocupado com o fumo, e a tarde, com chimarrão (segundo relatos, feito com quantidade irrisória de erva-mate). Verificou-se a inexistência de materiais de lazer, a não ser alguns aparelhos de televisão, transmitindo imagens com péssima qualidade de visualização.

As histórias de vida e registros sobre história pregressa e rotina dos residentes eram escassos, bem como o número de documentos pessoais e cartões bancários encontrados no local. Por conta do noticiado na mídia, familiares começaram a procurar a casa para obter notícias de seus familiares e retirá-los do local. De maneira geral, não foi percebida nenhuma alteração comportamental expressiva diante da intervenção e da nova equipe que ali se encontrava - o que causava preocupação na equipe técnica, diante das mudanças que viriam a ocorrer. Quando questionados, os técnicos conversavam com os residentes, esclarecendo o que estava acontecendo e os motivos que levaram a tal quadro. Não houve por parte dos mesmos, nenhuma resistência negativa com relação a intervenção, ocorreu justamente o contrário: os residentes agradeciam pelo cuidado que estavam recebendo, pela comida, pelas roupas novas e organizadas e pelo simples fato de estarem sendo ouvidos.

Como nos traz Carneiro \& Rocha (2004), o paciente internado há tantos anos em uma instituição psiquiátrica passa por um longo processo de desconstrução da personalidade. É despojado de suas referências pessoais, hábitos e relações sociais; o sujeito entra no anonimato promovido pelas estruturas institucionais. Ocorre uma despersonalização, ao final da qual o sujeito se identifica com a categoria de doente mental. Esse processo é abordado por Goffman (1990), que tanto contribuiu para esclarecer os mecanismos pelos quais as instituições totais (hospícios, prisões, conventos etc.) agem nos sentimentos de identidade e na construção da pessoa 


\section{Nanduty}

ISSN:2317-8590

estigmatizada, com ou sem o seu consentimento.

Trata-se, então, de um local que abriga sujeitos que se encontram em situação de suspensão de cidadania, isto é, nas palavras de Agamben (2002), a vida nua, uma vida que se define pela sua exclusão, enquanto não pertencimento, vida abandonada, uma vida de valor menor, definindo-se por sua proximidade com a morte justamente por sua vulnerabilidade, exposto que está por um ato jurídico que a exclui do direito e inclui em uma zona de abandono. Esta dimensão constitui a forma de gestão populacional dos indesejados, em que algumas vidas serão consideradas abjetas e colocadas em uma zona de anomia a qual fica à mercê da vontade soberana, que pode ser o médico ou o jurista.

Para Pereira (2017), seguindo esse debate para pensar a relação entre manicômio e loucura, destaca que as pessoas em sofrimento psíquico grave possuem garantias de direitos em diferentes dispositivos legais do ordenamento jurídico de tal modo que o estado de exceção em que vivem mostra-se paradoxal porque não existe um ato jurídico que suspenda os direitos desses sujeitos. Mas como excluídos tornam-se invisíveis para o direito, tendo a condição de vida nua reconhecida por este, uma vez que a instituição é antes de tudo um espaço de eliminação contínua de vidas desqualificadas.

As vidas despejadas em instituições manicomiais guardam, formalmente, o estatuto jurídico da cidadania. A exceção não decorre de um decreto, mas de "leis protetivas" que vigoram sem significar. A lei que se sustenta unicamente como ponto zero de seu conteúdo e a decretação do estado de exceção acabam por produzir os mesmos efeitos de poder na realidade: o a(bando)no da vida humana a uma zona anômica, a transformação dessa vida em homo sacer (Pereira 2017: 146).

Esse excesso imanente que causa espanto porque, como diz Biehl (2008: 440), a "intratabilidade e a impossibilidade de certas formas de vida humana acontecem em paralelo com exploração de mercado, dominação por gênero, novos padrões de consumo e um Estado administrado no que podemos chamar de estilo gerencial, cada vez mais distante do povo que ele governa", coloca esses corpos em uma situação de exclusão. $\mathrm{O}$ autor, que se aproxima desse debate de Agamben, afirma que tal ato seria um registro de morte social sancionada relacional e burocraticamente, em que humano, mental e fármaco tornam-se cúmplices de um processo que precariza as vidas e fazem com que as perdas de laços sociais se tornem irreversível, em alguns casos.

Esses espaços criados com o objetivo de cuidar daqueles que estão 


\section{Nanduty}

ISSN:2317-8590

vulnerabilizados apresentam-se diante de nossos olhos como espaços de exceção que expõem a todos à violência e as violações de direito, deixados para morrer aos poucos. Por isso, sob a premissa de que a Assistência Social como política pública rege-se pelos princípios da supremacia do atendimento às necessidades sociais e a universalização dos direitos sociais, a fim de tornar o destinatário da ação assistencial alcançável pelas demais políticas públicas, que a STAS foi chamada a envolver-se neste processo.

O primeiro questionamento foi de como iríamos construir cidadania e autonomia naquele lugar? Era muito difícil desconstruir as relações manicomiais e pensar alternativas, pois a divergência de entendimento e envolvimento dos/as técnicos/as, aliados com as dificuldades de compreensão do lugar da assistência social durante todo o processo e mesmo enquanto uma política pública voltada à garantia dos direitos de cidadania fazia novamente com que o quadro em tela fosse tratado como "atípico", não construindo ligações intersetoriais entre as diversas políticas públicas. O envolvimento, nesse contexto, deu-se a partir do trabalho técnico visando o resgate da cidadania e identidade negados a essas pessoas, que se encontravam em regime de segregação desumana, com graves violações de seus direitos perpetrados diariamente na instituição que deveria protegê-los.

Os serviços da rede socioassistencial do município passaram a priorizar o acompanhamento dos residentes da Perpétuo Socorro: os Centro de Atenção Psicossocial 2 e de Álcool e outras Drogas pela Secretaria de Saúde e os CRAS e o CREAS pela Secretaria de Trabalho e Ação Social - STAS. Todavia, o acompanhamento por parte da assistência social só ocorreu após muita discussão interna, pois o entendimento dos/as técnicos/as dos serviços divergiu (e ainda diverge) durante todo o processo.

Os/as residentes que possuíam algum diagnóstico de transtorno mental ou histórico de uso abusivo de álcool ou outras drogas eram acompanhados pelos CAPS 2 e AD; os/as idosos/as e pessoas com deficiência eram assistidos pelos CRAS e CREAS. O objetivo inicial era a desinstitucionalização: a saída dos/as residentes daquela instituição para suas famílias e/ou municípios de origem; primando pela execução do processo de desinstitucionalização, no sentido semântico da palavra "processo". O prazo estipulado judicialmente era de noventa dias. As ações deveriam ser continuadas, com o acompanhamento pela rede socioassistencial, tanto de Cachoeira, quanto dos municípios 


\section{Nanduty}

ISSN:2317-8590

de origem.

O Estado, através da $8^{\mathrm{a}}$ Coordenadoria Regional de Saúde realizava o contato com as coordenadorias regionais dos municípios que possuíam residentes no local. Os técnicos de Cachoeira também contatavam a rede do município que receberia seu munícipe de modo a fomentar a organização da mesma para o acompanhamento posterior. Dois Serviços Residenciais Terapêuticos (SRT) foram abertos para abrigar, prioritariamente, os/as residentes cachoeirenses e alguns/mas que não foram possíveis os restabelecimentos dos vínculos familiares ou até mesmo a localização de qualquer familiar; promovendo um novo sentido para aqueles/as residentes do que é o cuidado.

Neste passo, a resistência e a incredibilidade eram uma constante também de profissionais das diferentes políticas. Muitos, igualmente, contavam com ruídos de comunicação de sua rede interna e com a empatia de outros "resistentes" que nadavam contra a maré. Sob a égide de minimizar as violações sofridas e de fortalecer os vínculos familiares é que se desenhou uma prática de trabalho da política de assistência social balizada por perspectiva de garantia de direitos, embora com precária discussão sobre o lugar de cada área técnica-profissional nesse processo.

Durante as várias discussões sobre o trabalho de intervenção foi se evidenciando que as visões sobre o lugar de cada nível de proteção social da assistência social eram diferenciadas. Os/as técnicos/as da proteção social básica asseguravam que o fato das pessoas estarem institucionalizadas por si só já caracterizava violação de direitos, pelo rompimento dos vínculos familiares. Os/as técnicos/as da proteção social especial alegavam que, por mais contraditório que pudesse parecer, mesmo institucionalizadas, algumas pessoas ainda mantinham os vínculos familiares, necessitando de trabalho de fortalecimento destes (de modo a evitar o rompimento); que é atribuição da proteção básica.

Esse processo colocava em circulação uma série de discursos profissionais e compreensão sobre o papel de cada política pública e nível de proteção, gerando tensionamentos sobre quais as possibilidades de um processo de desinstitucionalização em curso. As reuniões técnicas invariavelmente terminavam em acordos pontuais, justificados pela condição insólita de casos, já que as discussões não avançavam. Ora por resistência e compressões particulares de técnicos/as sobre a questão em pauta, ora pela justificativa de excesso de demanda e ausência de recursos humanos e materiais - o 


\section{Nanduty}

ISSN:2317-8590

que não deixava de ser um dificultador da efetivação no processo, tanto na assistência social, quanto na saúde.

Assim, observamos a cada debate o retorno a necessidade de sensibilização e identificação individual de cada técnico/a à dimensão do sofrimento e vulnerabilização, acionando uma gramática da compaixão para que o trabalho pudesse fluir de algum modo. Esse processo marca uma forma de gestar o sofrimento, em que a constante referência aos casos particulares para mobilizar a intervenção dos diferentes níveis de proteção aponta para o modo como há uma transformação da dor e sofrimento em linguagens profissionais como apropriação das experiências e a voz dos sujeitos para moldar as respostas do Estado às situações de violência ou do acesso destes aos direitos sociais e da saúde (Das 1995; Fassin 2005).

Como argumentam Ortega (2008), Kleinman et al. (1997) e Das (1995) há uma gestão do sofrimento pelo Estado através da linguagem profissional sobre os corpos daqueles que vivenciam processos de violência. Os discursos e práticas de especialistas geram uma taxonomia que procura explicar os eventos que demandam atenção do Estado e têm como consequência apropriar-se da voz dos e das experiências dos sujeitos, destituindo o mundo moral e a dimensão experiencial da de dor. Como afirma Ortega (2008: 37-38, grifo do autor),

ese proceso de expropiacion se agrava em aquellos casos en que el Estado o instituciones supranacionales recurren exclusivamente a estos lenguajes para determinar, despues de un engorroso y con frecuencia degradante proceso, la gravedad y pertinencia del sufrimiento; es esa exclusividad la que transforma la dimension personal del agravio en una consideracion de calculo de razon de Estado; es ella la que convierte victimas en cuerpos colonizados por el poder soberano del Estado.

As ações, nesse contexto, no que diz respeito à política de assistência social, ficavam na esfera de violação de direitos, encabeçadas e priorizadas pelos técnicos do CREAS e algum outro serviço no sentido de "ajudar" com esta demanda. Nota-se que essa política colabora com o trabalho, mas não se articula em ações intersetoriais ou acenando com recursos financeiros, dada a dificuldade de se encontrar e identificar este processo como pertencendo a essa política. Tendo participado desde o fortalecimento dessas zonas até a participação ativa desde o início do processo de desinstitucionalização, ao inserir-se nos grupos responsáveis por levantamento de dados 


\section{Nanduty}

ISSN:2317-8590

e reuniões de trabalho para construir alternativas ao modo de cuidado aos residentes, o que se percebe são as contradições internas de uma política pública que sempre esteve participando.

\section{À GUISA DE CONCLUSÃO}

Nessa breve trajetória apresentada procurou-se pensar Estado e políticas públicas como constituindo uma máquina de fazer viver e deixar morrer a partir de diferentes tecnologias que produzem sujeitos e zonas de abandono social em uma relação complexa com o setor privado, observamos que o processo de desinstitucionalização tem sido marcado por contradições no fazer cotidiano da política municipal de assistência social. A despeito de ter emergido com o objetivo de promover cidadania, essa política, em um contexto neoliberal e de privatização do cuidado, tem contribuído para a produção de zonas de abandono, na medida em que fez uso das casas lares para encaminhar pessoas com mais de 60 anos, ao mesmo tempo em que está implicada no processo de desinstitucionalização.

Ao apresentar a genealogia desse processo, observou-se as ambiguidades desse processo e as tensões que foram se constituindo e produzindo diferentes modos de fazer a política pública, bem como o lugar, nem sempre claro para os/as técnicos/as e gestores, ocupado pela política de assistência social Percebe-se pelo exposto que a política de assistência social foi pautada neste processo pelo entendimento e identificação de alguns técnicos, no viés de violação de direitos humanos, com entendimentos variados sobre as ações e discussão para fomentar/implementar a transversalidade do tema saúde mental na assistência social.

A incumbência de seguir com esse mote de reflexão ainda é parte de discussão. Alguns poucos profissionais - atualmente aqueles que foram sugeridos pela gestão municipal nominalmente ao Ministério Público e aqueles que se afinam com o tema e com sua representatividade na política pública, tem suscitado esse debate com maior frequência. Há ainda o embaraço dos gestores em implementar política pública em um contexto novo em governos que não a priorizam, pois no que diz respeito à desinstitucionalização, tanto a gestão municipal quanto estadual, diferentemente daquelas da culminância do processo, e a particularidade do município não tem colocado a demanda como prioridade, visto sequer haver discussão e planejamento 


\section{Nanduty}

ISSN:2317-8590

governamental para pensar política pública para essa população. Esse processo ainda se encontra em curso e, entende-se, ser importante a reflexão dos acontecimentos até o momento, considerando que passados mais de 10 anos ainda se está discutindo qual o lugar da assistência social e como construir políticas de cuidado às pessoas ainda institucionalizadas nas casas lares.

\section{REFERÊNCIAS BIBLIOGRÁFICAS}

AGAMBEN, Giorgio (2002). Homo Sacer: o poder soberano e a vida nua. Belo Horizonte, UFMG.

BRASIL. Ministério do Desenvolvimento Social e Agrário. Secretaria Nacional de Assistência Social. (2004). Política Nacional de Assistência Social - PNAS. Brasília.

BIEHL, João. (2008). "Antropologia do devir: psicofármacos - abandono social desejo". Revista de Antropologia, São Paulo, 51(2): 413-449.

CARNEIRO, Nancy Greca de Oliveira; ROCHA, Luciana de Carvalho. (2004). "O processo de desospitalização de pacientes asilares de uma instituição psiquiátrica da cidade de Curitiba". Psicologia, Ciência e Profissão, Brasília, (24)3: 66-75.

DAS, Veena. (1995). "The Anthropology of Pain". In: _. Critical events: an anthropological perspective on contemporary. India, New Delhi, Oxford University Press, p. 175-196.

; POOLE, Das. (2008). "El Estado y sus márgenes: etnografias comparadas". Revista Cuadernos de Antropología Social, Buenos Aires, (27): 19-52.

DECRETO MUNICIPAL Nº. 120, 2013, Cachoeira do Sul.

FASSIN, Didier. (2005). "Gobernar por los cuerpos, políticas de reconocimiento hacia los pobres y los inmigrantes". Educação, Porto Alegre, (28)2: p. 201-226.

FOUCAULT, Michel. (2002). "Aula de 17 de Março de 1976". In: Em Defesa da Sociedade. Curso no Collège de France. São Paulo, Martins Fontes, p. 285-315.

GOFFMAN, Erving. (1988). Estigma: Notas Sobre a Manipulação da Identidade Deteriorada. $4^{\mathrm{a}}$ ed. Rio de Janeiro, Editora Guanabara.

GOFFMAN, Ervin. (1961). Manicômios, Prisões e Conventos. São Paulo, Editora Perpectiva..

KLEINMAN, Arthur et al. (1997). "Introduction". In: Social Suffering. Berkely, University of California Press.

OLIVEIRA, Joana Angélica Macedo; PASSOS, Eduardo. (2007). A implicação de serviços de saúde mental no processo de desinstitucionalização da loucura em Sergipe. Vivência, Natal, (1): 259-275.

ORTEGA, Francisco. (2008). "Rehabitar la Cotidinidad". In: . (org.). Veena Das: Sujetos del Dolor, Agentes de Dignidad. Bogota, Universidad Nacional de Colombia. PEREIRA, Gabriela Simões. (2017). "O campo, a exceção e a vida nua: uma leitura da instituição total manicomial”. Profanações, Mafra, (4) 1: 145-161.

PORTARIA No. 106, 2000.

PORTARIA Nº. 3090, 2011.

RESOLUÇÃO 109, 2009.Tipificação Nacional dos Serviços Socioassistenciais, Brasília.

SADIGURSKY, Dora; TAVARES, José Lucimar. (1998). “Algumas considerações 


\section{Nanduty}

ISSN:2317-8590

sobre o processo de desinstitucionalização". Revista Latinoamericana de Enfermagem, Ribeirão Preto, (6) 2: 23-27.

SHORE, Cris. (2010). "La antropologia y el estudio de la política pública: reflexiones sobre la "formulación" de las políticas". Antipoda, Revista de Antropologia y Arqueologia, Bogotá, (10): 21-49. 